\title{
Experimental study on segmental stability of mandibular osteotomy: Bioresorbable mesh versus titanium osteosynthesis
}

\author{
Min-Keun Kim, Young-Wook Park* \\ Department of Oral and Maxillofacial Surgery, College of Dentistry, Gangneung-Wonju National University, Gangneung, Korea
}

\begin{abstract}
We compared the segmental stability of hydroxyapatite (HA)/poly-L-lactide (PLLA) mesh for the osteofixation of mandibular osteotomy to that of titanium osteofixation. A mandibular discontinuity was created in ten rabbits, whereby either a HA/PLLA mesh or a titanium miniplate was used for osteofixation. Postoperatively, the amount of daily feed intake was measured and radiographic images were captured. At sacrifice, occlusion was checked and histologic evaluations were performed with H\&E and Masson's trichrome staining. From the results, the HA/PLLA mesh-fixation group showed a higher daily feed intake compared to that in the titanium-fixation group. At sacrifice, occlusion was more stable in the HA/PLLA mesh-fixation group. Histologically, fibrous union was detected in the titanium-fixation group. In conclusion, HA/PLLA mesh-osteofixation demonstrated superior to titanium-osteofixation.
\end{abstract}

Key Words: Mandibular osteotomy, Bioresorbable-osteofixation, Titanium-osteofixation, Segmental stability

(c) This is an open-access article distributed under the terms of the Creative Commons Attribution Non-Commercial License (http://creativecommons.org/licenses/by-nc/4.0) which permits unrestricted noncommercial use, distribution, and reproduction in any medium, provided the original work is properly cited.

\section{서 론}

한국인에서 많이 관찰되는 발육성 턱얼굴 변형증은 정면에서 의 얼굴 비대칭을 포함하거나 또는 포함하지 않은 하악골 전돌 증이다[1]. 하악골 전돌증을 치료하기 위해서는 하악 골편을 근 육이나 골조직 저항이 존재하는 후방으로 이동시켜야 한다. 최 근 들어 작은 얼굴을 선호하는 환자들의 심미적 요구에 따라 상 악골 후방 함입(maxillary posterior impaction)과 같은 술식에 의해 하악 골편의 후방 이동량은 더욱 증가되었다. 또한 안모의 빠른 개선을 위한 선수술(surgery first)과 같은 치료가 시행되면 서 불완전한 교합상태에서 턱교정 수술이 수행됨에 따라 수술 시 안정적인 골고정술(osteofixation)은 더욱 요구된다[2].

턱교정 수술 후 장기적인 골격 안정성을 보장하는 골고정술
로는 타이타늄 플레이트가 가장 효율적인 방법으로 여겨져 왔 다[3]. 최근에는 인체 내의 타이타늄 고정체가 합병증을 야기하 지 않는 한, 제거하지 않는 경향도 있다[4]. 그러나 타이타늄 플 레이트를 제거하지 않을 경우 청소년기 환자의 골 성장에 지장 을 초래할 수 있고, 인체 내에서 타이타늄은 이물질로 작용하여 주변 조직에 병소를 발생시킬 우려가 있다[5]. 게다가 방사선학 적 평가 시 항상 방해가 되는 문제점이 지적되고 있다. 따라서 아직도 많은 임상가들은 타이타늄 플레이트 제거를 위한 이차 수술을 시행하고 있으며, 환자들은 이차수술의 불편함을 감수 하고 있다.

따라서 제거가 필요하지 않은 흡수성 플레이트의 필요성이 오래 전부터 인식되었으나, 흡수성 물질의 강도 부족으로 인하 여 제한적으로 턱얼굴 수술에 적용된 바 있다[6,7]. 2000년경

Received April 25, 2018; Revised June 20, 2018; Accepted July 9, 2018

Corresponding author: Young-Wook Park, Department of Oral and Maxillofacial Surgery, College of Dentistry, Gangneung-Wonju National University, 7 Jukheon-gil, Gangneung 25457, Korea.

Tel: +82-33-640-3183, Fax: +82-33-640-3103, E-mail: ywpark@gwnu.ac.kr

Copyright $\odot$ 2018, Oral Biology Research Institute 
부터 강도가 강화된 흡수성판(resorbable plate)들이 제품화되 면서 턱교정 수술에 적용되기 시작하였다. Poly-L-lactic acid (PLLA)를 주성분으로 하는 흡수성판은 턱교정 수술에 적용 시 골편의 조기 안정도가 결여된다는 임상적 보고 외에도 그 장단 점에 관한 다양한 결과들이 보고되었다[8-11].

최근에는 PLLA에 골전도(osteoconduction) 작용이 있 는 hydroxyapatite $(\mathrm{HA})$ 가 결합하여 강도가 강화됨과 동시 에 흡수와 함께 주변 조직의 골전도를 촉진하는 생흡수성 판 (bioresorbable plate)의 개념이 도입되었다[12,13]. 이에 본 연 구에서는, 공간 구조의 장점을 임상적으로 이용할 수 있는 $\mathrm{HA} /$ PLLA 생흡수성 메쉬를 적용하였을 때의 골편의 안정도를 타이 타늄 플레이트를 적용하였을 때와 실험적으로 비교하고자 하였 다.

\section{대상 및 방법}

본 실험은 강릉원주대학교 동물실험윤리위원회의 심의(승인 번호: GWNU-2017-6) 후 진행되었다.

\section{실험동물}

12주된 수컷 New Zealand 흰 토끼를 업체(Samtaco, Seoul, Korea)로부터 구입하여 이용하였다. 개체의 몸무게가 $2.0-2.5 \mathrm{~kg}$ 에 이르렀을 때 수술을 시행하였으며, 실험군과 대조군의 개체 수는 각각 5 였다.

\section{동물수술}

전신마취를 유도하기 위하여 Zoletil 50 (15 mg/kg; Vibac Korea, Seoul, Korea)과 Rompun $(0.2 \mathrm{~mL} / \mathrm{kg}$; Bayer Korea, Seoul, Korea)을 근육주사 하였다. 악하 절개를 통하여 하악골 우측을 노출시킨 후 임상에서 사용한 것과 동일한 타이타늄 미 니 플레이트나 생흡수성 메쉬판을, 골절단 전에 미리 하악골 외 형에 적합시켰다. 소독된 기공용 디스크를 이용하여 소구치 전 방부에 simple continuity defect를 형성한 후 타이타늄 플레이 트(M3; Osteomed Co., Addison, TX, USA; 대조군)나 $0.5 \mathrm{~mm}$ 두께의 unsintered HA (u-HA)/PLLA 메쉬판(OsteotransMX; Takiron, Osaka, Japan; 실험군)을 적용하였다. 실험군에서는 $4 \mathrm{~mm}$ 길이의 u-HA/PLLA 스크류를 골편당 3개씩 고정하였 고, 대조군에서는 $6 \mathrm{~mm}$ 의 타이타늄 스크류를 골편당 2개씩 적 용하였다. 수술 창상은 층별 봉합하였다(Fig. 1). 수술 후 5일간 $0.5 \mathrm{~mL} / \mathrm{kg}$ 의 Pyrin (Green Cross Veterinary Products, Seoul, Korea)과 Gentamicin을 근육주사하였고, 한 마리씩 케이지에 넣고 사료와 물을 공급하였다.

\section{실험동물의 유지와 희생}

토끼 하악골의 기능적 회복은 하루 음식섭취량(daily feed intake amount)을 분석하여 평가하였다[14]. 기준을 잡기 위하 여 수술 전에 각 실험동물의 하루 음식섭취량을 7일 동안 체크 하였다. 수술 후에는 희생 시까지 각 개체의 하루 음식섭취량을 측정하여 수술 전 기준량에 대한 백분율로 표시하였다.
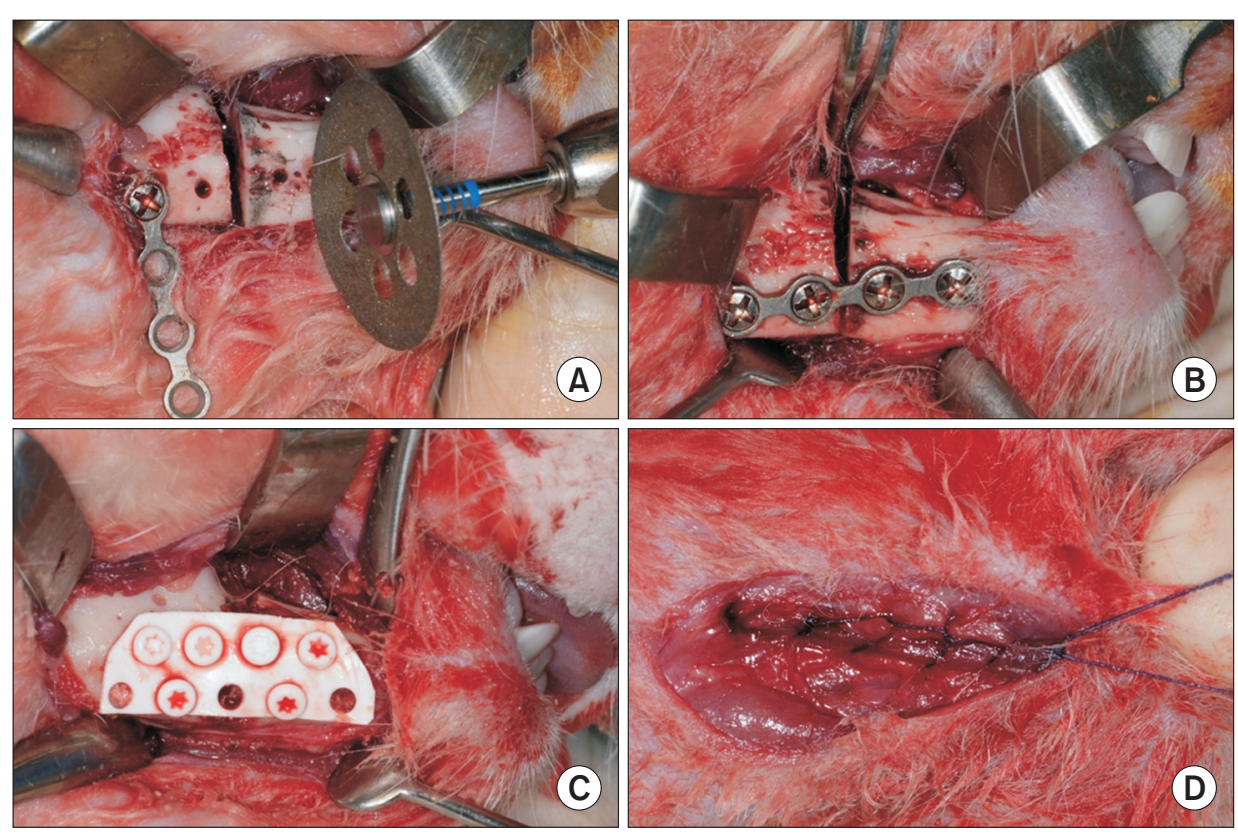

Fig. 1. Photographs of animal experiments. (A) After adaptation of a 4-hole titanium plate, we induced a simple continuity defect in the mandibular body of a rabbit by using a disk. (B) Titanium-osteofixation for the simple continuity defect of the mandible. (C) Bioabsorbables-osteofixation for the simple continuity defect of the mandible. (D) After osteofixation, layer suture was performed. 
수술 직후와 수술 후 1 개월, 2 개월, 그리고 3 개월 시점에서 실 험동물의 하악골 골유합 정도와 고정 장치의 상태를 방사선 사 진를 촬영(X-ray generator HEL-S; 노출시간은 0.1초)하여 평 가하였다. 수술 후 3 달 시점에서 실험동물을 희생하여 플레이 트의 상태와 screw loosening을 계수하였다. 또한 플레이트 주 변 연조직을 포함한 시편을 제작하여 H\&E 염색과 Masson's trichrome 염색을 수행하였다.

\section{통계}

하루 음식섭취량을 차이를 검정하기 위하여 수술 후 2일 마다 의 군간의 평균값을 Mann-Whitney test로 비교하였다.

\section{결 과}

\section{하루 음식섭취량}

실험동물은 모두 전신마취와 수술로부터 회복되었다. 토끼 하악골의 기능적 회복을 평가하기 위하여 하루 음식섭취량의 변화를 분석한 결과 Fig. 2에서와 같이 실험군이 대조군과 비교 하여 높은 하악골 기능 회복률을 나타내었다. 실험군과 대조군 모두에서 술 전 하루 음식섭취량의 회복은 수술 후 10 일경에 이 루어졌다. 이후 시간이 경과하면서 특히 대조군에서 하루 음식 섭취량이 감소하여 통계적으로 유의한 차이는 수술 후 88 일째 부터 나타났다.

\section{방사선 소견}

방사선 사진을 분석한 결과, Fig. 3에서와 같이 실험군과 대조 군 모두에서 수술 직후에 관찰되었던 골 절단선의 방사선상이 1 개월에서 2개월 사이에 모두 소실되었다. 즉 고정체에 따른 하 악골유합의 정도는 방사선상에서 차이가 없었다. 또한 사용된 고정장치의 상태는 방사선상에서 안정적으로 유지되었으며, 주 변 골조직의 소실은 관찰되지 않았다.

\section{희생 시 소견}

희생 시 교합을 수술 직후의 교합과 비교한 평가 결과 실험군 에서 3 개체, 대조군에서는 1 개체만이 안정적인 교합이 유지되 었다(Fig. 4). 나머지 개체에서 관찰된 부정교합을 전방과 후방 의 교합으로 구분하여 평가하였을 때, 그 결과는 Table 1 과 같 았다. 하악골 고정 부위를 노출하였을 때 육안적으로 모든 개체 에서 골유합이 잘 이루어졌고 플레이트의 상태 역시 두 군 모 두에서 안정적으로 유지되었다. 그러나 스크류는 실험군에서 는 모두 견고하게 유지된 반면, 대조군에서는 $20 \%$ 의 스크류가 loosening된 소견을 나타내었다(Table 2, Fig. 5).

\section{조직학적 소견}

플레이트 주변의 연조직 소견을 $\mathrm{H \& E}$ 로, 골조직 소견을 Masson's trichrome 염색으로 관찰하였다. 두 군 모두에서 고 정체 주변의 연조직에서 염증성 이물반응은 관찰되지 않았다.

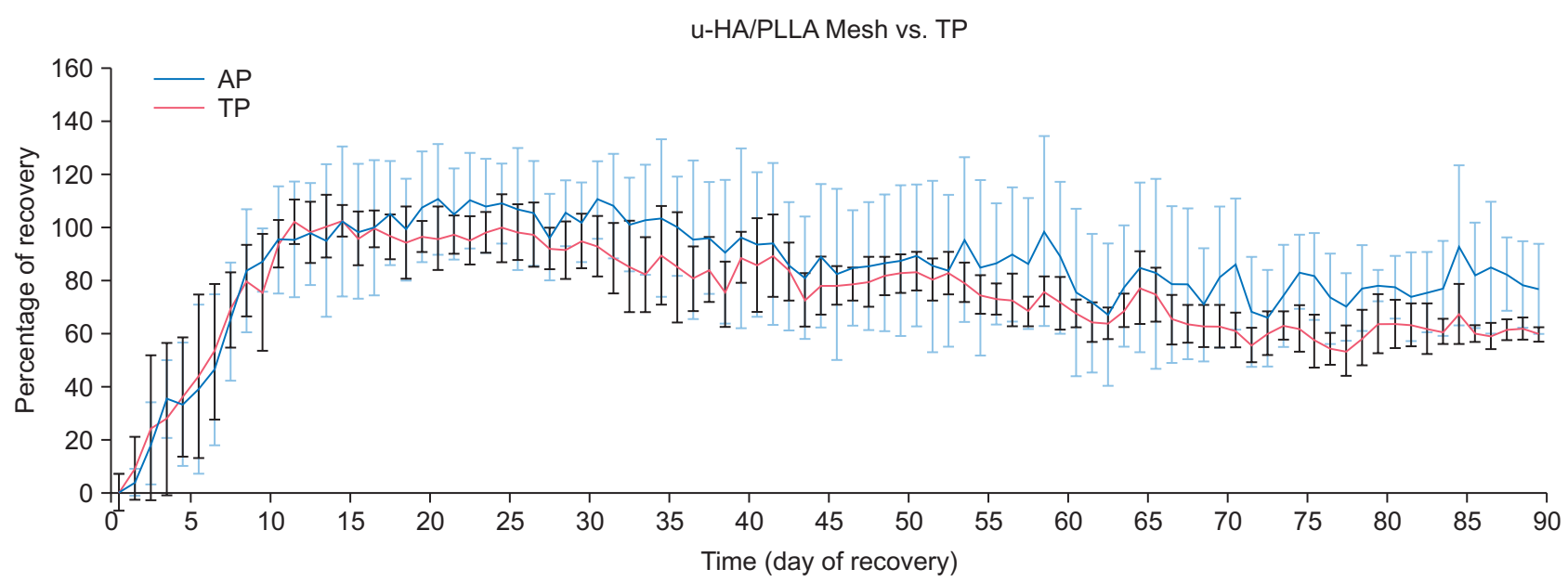

Fig. 2. For each rabbit, daily feed intake amount was measured for 7 days prior to surgery to obtain the baseline level of daily feed intake amount. Postoperatively, daily feed intake amount was measured for 3 months. To compare functional rehabilitation between groups, the daily feed intake amount was compared to its control value. Bar represents the standard error. u-HA, unsintered hydroxyapatite; PLLA, poly-L-lactic acid; AP, absorbable plate; TP, titanium plate. 

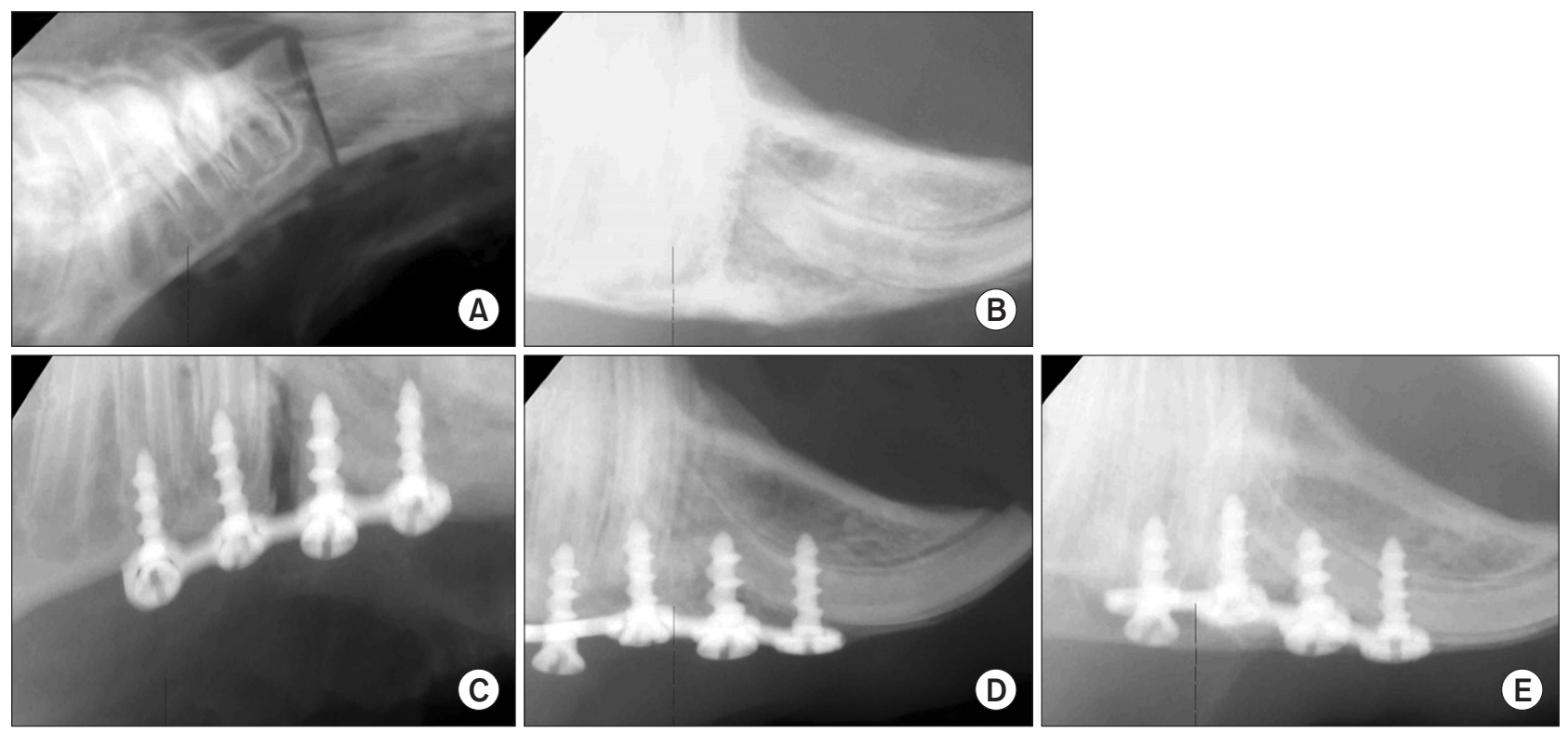

Fig. 3. Radiographic images of rabbit mandible in $(A, B) \mathrm{u}-\mathrm{HA} / \mathrm{PLLA}$ group and (C-E) titanium group. Representative images are shown at the $(\mathrm{A}, \mathrm{C})$ time of immediately postoperatively, (B, D) 1 month postoperatively, and (E) 2 months postoperatively. u-HA, unsintered hydroxyapatite; PLLA, poly-L-lactic acid.

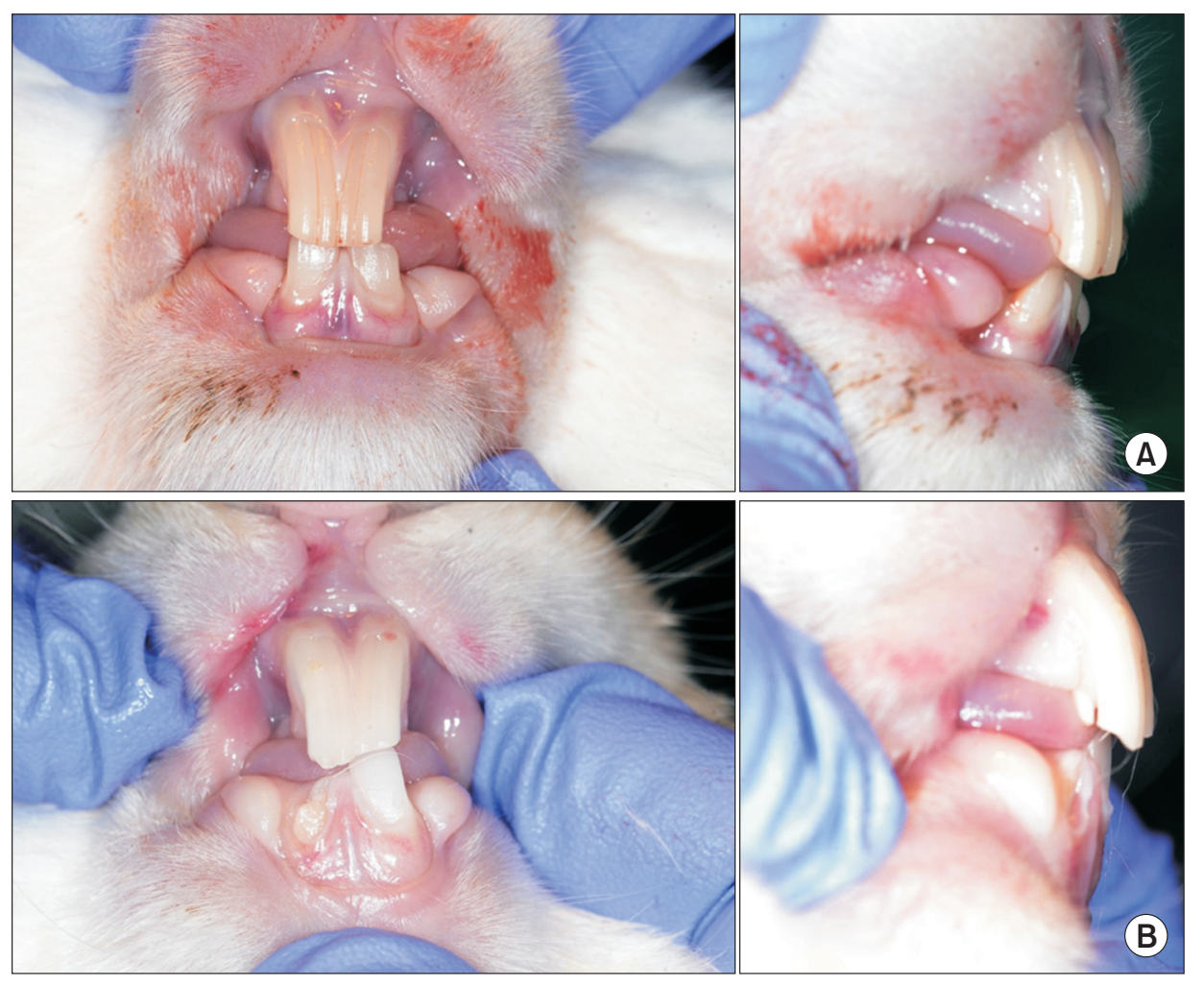

Fig. 4. Representative photographs of (A) occlusion at the time of sacrifice in u-HA/PLLA group and (B) titanium group. Occlusal instability was revealed in titanium group. u-HA, unsintered hydroxyapatite; PLLA, poly-L-lactic acid.
골절단 부위에서의 골유합은 전반적으로 이루어졌으나 대조군 의 일부 개체에서 섬유성 결합이 관찰되었다(Fig. 6). 편광현미 경 관찰 결과 실험동물의 하악골은 해면골로부터 활성화된 새
로운 골조직으로 치유되어 12주에 완전한 골개조가 이루어졌다 (Fig. 7), 흡수성 메쉬 주변에 국소화된 육아종성 조직이 관찰되 기도 하였지만, 다형핵백혈구의 침윤은 관찰되지 않았다. 


\section{고 찰}

본 연구에서는 턱교정 수술 시 골편 고정에 적용 가능한 생 흡수성 메쉬의 골편 안정성을 타이타늄 플레이트와 실험적으 로 비교하였다. 즉, 토끼의 하악골 불연속 모델(mandibular discontinuity model)에서의 동물실험을 통하여 생흡수성 메쉬 와 타이타늄 플레이트 고정 시 골격 안정성에 따른 하악골의 기 능과 골유합에 관한 조직소견을 관찰하여 생흡수성 메쉬에 대 한 의미있는 결과를 도출하였다.

PLLA의 광학적 이성질체에 대한 중합반응을 통하여 적절한 강도가 확보된 흡수성 플레이트들이 턱교정 수술에 적용되어 다양한 임상적 결과가 보고된 바 있다[15-18]. 일부에서는 강도 가 보강된 흡수성 플레이트도 수술 직후의 골편 안정성에 문제 가 있다는 지적이나, 혹은 일부 지표에서 타이타늄 플레이트와 비교하여 안정성이 떨어진다는 보고를 하였다[19]. 최근에 수술 기법의 발달과 함께 적용된 흡수성 플레이트는 임상적으로 안 정적이라는 보고들이 있지만[20,21] 본 연구에서처럼 메쉬 형 태의 생흡수성 판을 사용한 예는 없다. 저자의 임상적 경험과

Table 1. Incidence of malocclusion at sacrifice

\begin{tabular}{lcc}
\hline \multicolumn{1}{c}{ Group } & $\begin{array}{c}\text { Anterior } \\
\text { malocclusion }\end{array}$ & $\begin{array}{c}\text { Posterior } \\
\text { malocclusion }\end{array}$ \\
\hline u-HA/PLLA group & $2 / 5$ & $1 / 5$ \\
Titanium group & $4 / 5$ & $0 / 5$ \\
\hline
\end{tabular}

u-HA, unsintered hydroxyapatite; PLLA, poly-L-lactic acid.
선행연구[22,23] 결과 PLLA 중합체를 적용하여 견고고정을 유 도하는 것은 가능하다고 판단된다. 그러나 이를 위해서는 보다 큰 크기의 고정체가 필요하고, 이에 따라 수술 시 확장된 박리 (dissection)와 함께 고정시간이 더 걸린다는 단점이 있다.

본 연구의 대상이 된 흡수성 메쉬는 PLLA에 소결되지 않은 $\mathrm{HA}(\mathrm{u}-\mathrm{HA})$ 가 나노입자의 형태로 결합된 물질이다. 이론적으 로 이 물질은 인체로부터 가수분해되거나 $\mathrm{HA}$ 의 골전도성으로 인하여 이식된 후 4-5.5년 사이에 골조직으로 완전히 대체된다 [24]. 게다가 u-HA/PLLA는 생체 내에서 25주 동안 인간 피질 골과 같은 휨강도(bending strength)를 유지한다고 보고되었다 [25]. 따라서 하악골 시상분할골절단 부위에 타이타늄 플레이트 와 같은 크기인 미니사이즈의 4홀 u-HA/PLLA 플레이트도 적 용 가능하다고 판단된다. 그러나 저자는 저작근의 저작압이 집 중될 경우에는 금속판도 파절 가능하다는 점을 고려하여 메쉬형 u-HA/PLLA 나노복합체를 임상에 적용하고자 하였다.

본 동물실험에서는 임상에서의 하악골 시상분할골절단술을 토끼 하악골에 최대한 재현하고자 골결손 모델[26]보다는, 단순 골절단 모델을 적용하였다. 그 결과 하악골 골체부에 가한 골절 단선의 방사선 흡수상이 수술 후 1-2달 사이에 모두 소실되어

Table 2. Incidence of screw loosening at sacrifice

\begin{tabular}{cccc}
\hline \multicolumn{1}{c}{ Screw } & Intact & Loosening & Absent \\
\hline u-HA/PLLA group & 30 & 0 & 0 \\
Titanium group & 16 & 4 & 0 \\
\hline
\end{tabular}

u-HA, unsintered hydroxyapatite; PLLA, poly-L-lactic acid.
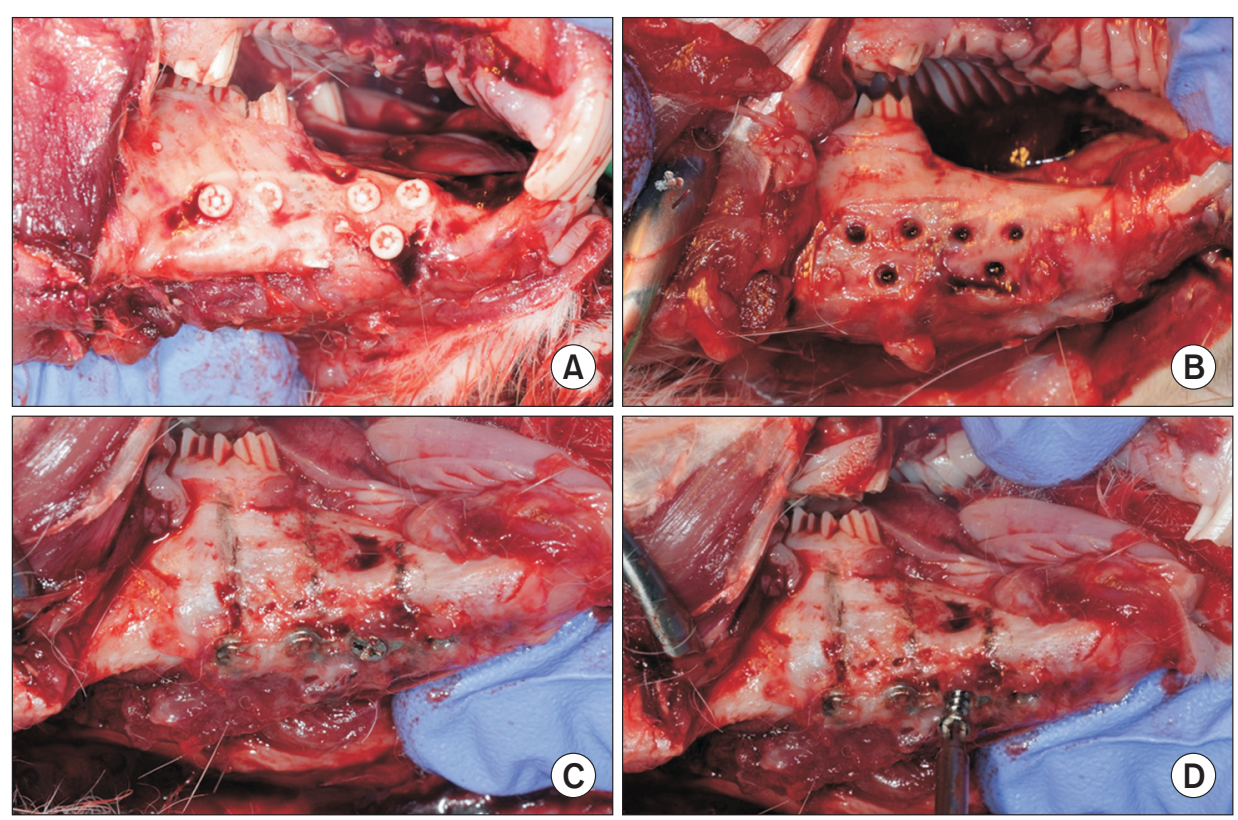

Fig. 5. Representative photographs of (A, B) fixative devices at the time of sacrifice in u-HA/PLLA group $(C, D)$ and titanium group. (A) Overgrowth of bony tissue in u-HA/PLLA group. (B) After removal of the fixative devices. (C) Overgrowth of bony tissue in titanium group. (D) A loose titanium screw was detected. u-HA, unsintered hydroxyapatite; PLLA, poly-L-lactic acid. 


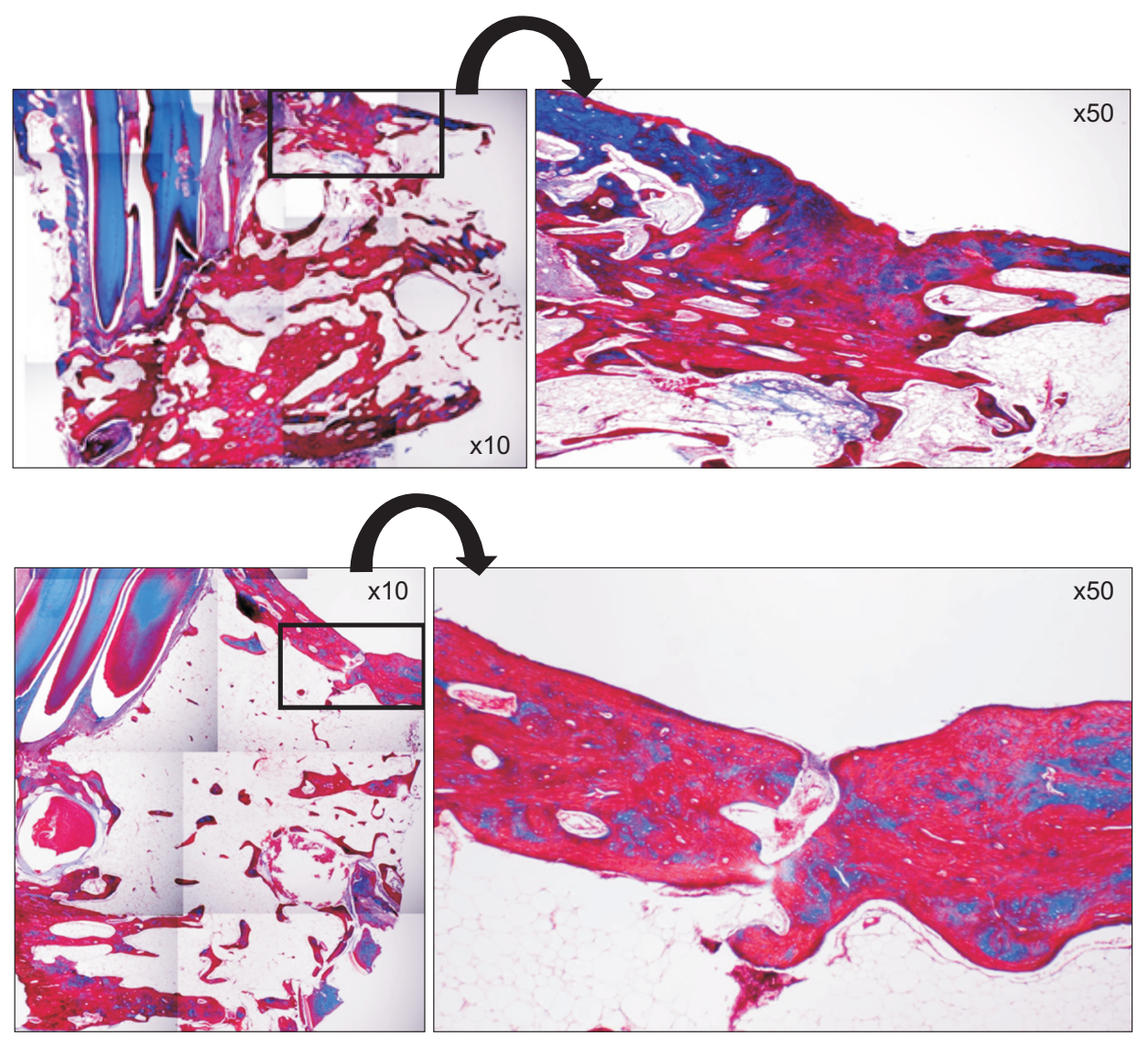

Fig. 6. Representative photographs of Masson's trichrome staining in $\mathrm{u}-\mathrm{HA} /$ PLLA group (upper panel; rabbit of number 3) and titanium group (lower panel; rabbit of number 1). Fibous gap was detected at the osteotomy site in titanium group. u-HA, unsintered hydroxyapatite; PLLA, poly-L-lactic acid.
고정 방식에 따른 하악골유합의 차이는 관찰되지 않았다. 그러 나 조직학적으로 타이타늄 고정군의 일부 개체에서 골절단 부 위가 골성 결합이 아닌 섬유조직성 결합으로 대체되었음이 관 찰되었다. 메쉬 주변에서는 국소화된 육아종성 조직이 존재하 였지만 급성 염증세포의 침윤은 관찰되지 않아 흡수성 메쉬의 이물반응은 퇴행적이지 않으며 괴사성 농양을 야기하지 않을 것으로 추정된다. 즉 흡수성 메쉬는 생체불활성과 함께 우수한 조직적합성을 보여주었다.

하루 음식섭취량으로 평가한 하악골의 기능 회복률과 희생 시까지의 기능 지속률은 메쉬 군에서 더 우수하게 나타났다. 또 한 수술 후 3개월이라는 희생시점에서 평가하여 보았을 때 부정 교합이나 스크류 loosening 발생 정도가 타이타늄군에서 더 높 게 나타났다. 이는 하악골 손상 후 골개조가 이루어질 때까지, 4 홀 타이타늄 미니플레이트보다 6개의 스크류를 적용한 생흡수 성 메쉬의 골편고정 효율성이 더 우수하고 결과적으로 수술 부 위에 대한 골격안정성도 더욱 우수하였다는 것을 반증한다. 부 정교합이 발생된 개체는 메쉬군에서 3개체, 타이타늄군에서 4 개체로 예상보다 많았다. 특히 전치부 부정교합을 보인 개체가 많았는데 이는 토끼의 경우 강한 저작기능이 전치부에서 이루 어짐으로 저작압이 전치부에 집중되었기 때문인 것으로 추정하
였다. 게다가, 본 실험에서 타이타늄 스크류의 경우 loosening 되는 비율이 높았다. Loosening 된 스크류는 주변조직에 염증 성 병소를 유발할 수 있으므로 반드시 제거해야 할 필요성이 있 음을 알 수 있다.

턱교정 수술에 적용하기 위한 흡수성 고정재료의 이상적인 특성은 골조직 치유기간 중 충분한 지지력을 제공한 후에는 가 능한 빨리 체내 대사과정에 의해 분해되면서 자극적인 잔여물 을 남기지 않는 것이다. 본 연구에서 관찰하지 못한 점은 흡수 성 고정체의 흡수과정에 의한 생체 내 조직반응이었다. 이는 적 용된 u-HA/PLLA 복합체의 생체 내 흡수반응이 일어나는 기간 을 고려해 볼 때 이식 후 3 개월의 희생시점에서 결과를 도출할 수 없었던 점은 본 연구의 한계라고 생각된다. 또한 본 연구에서 적용된 스크류의 개수가 다르다는 점이 고려될 수 있으나 타이 타늄과 생흡수성 판의 강도 역시 다르고, 무엇보다도 메쉬 고정 이라는 임상상황을 최대한 동물실험에 재현하면서 동시에 최소 한의 스크류 개수를 정한 것이다. 타이타늄 미니 플레이트의 경 우 하악골 시상분할골절단술 부위에 임상적으로 4홀 플레이트 를 적용하고 있음으로 이 역시 그대로 동물실험에 재현하여 비 교하였다.

결론적으로, 임상상황에서와 동일한 고정체를 토끼에 재현한 

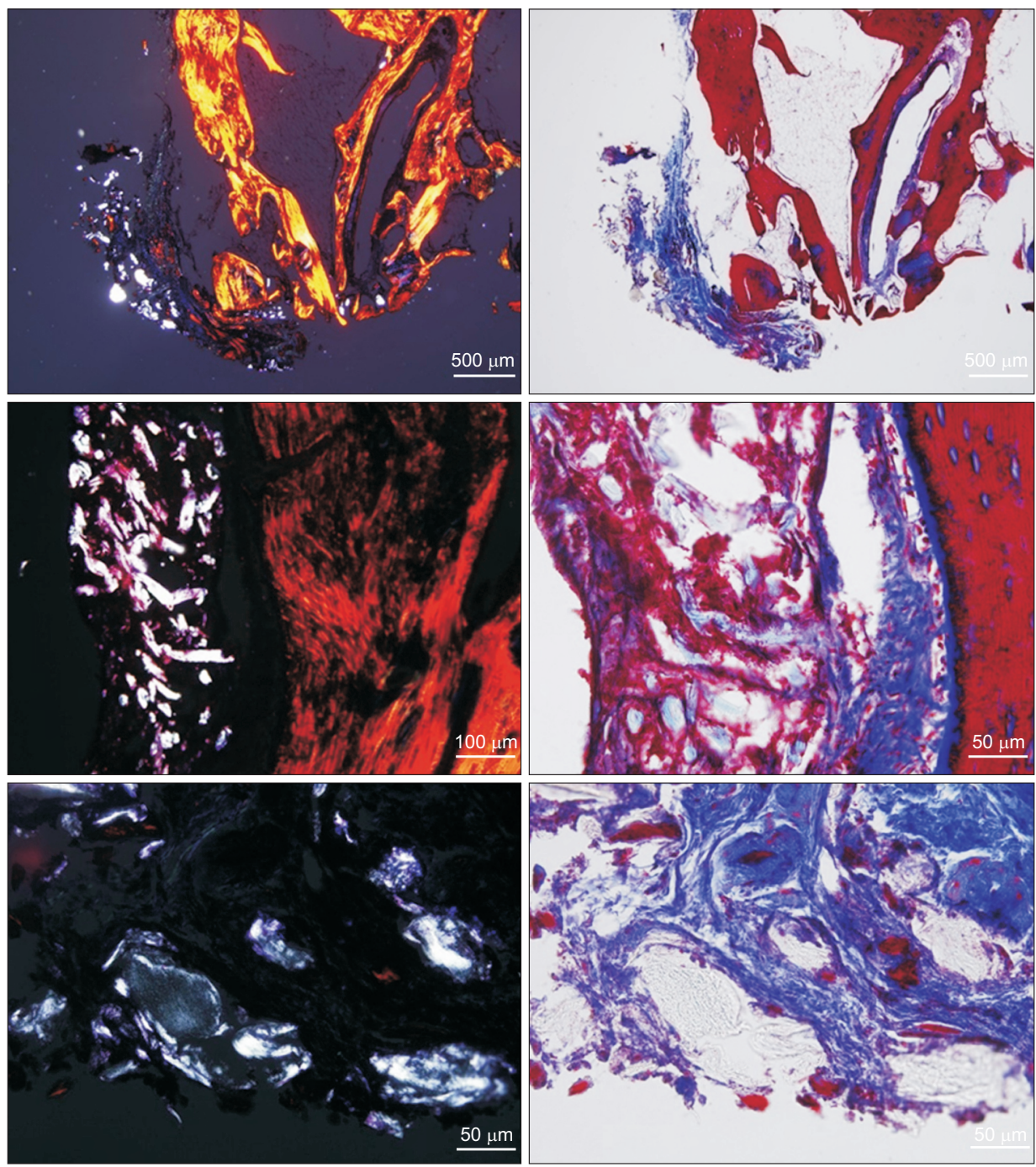

Fig. 7. Representative photographs of Masson's trichrome staining by polarizing light in u-HA/PLLA group. Although the bioabsorbable mesh was lack of osteogenic potential, the resected mandibular bones were rapidly healed with active and remarkable new bone formation from the trabecular bones of the host, and resulted in complete bony fusion in 12 weeks of experiment. u-HA, unsintered hydroxyapatite; PLLA, polyL-lactic acid.

동물실험 결과 생흡수성 메쉬 고정군에서 수술 후에 하악골 기 능 회복이 더 잘 이루어지고, 고정체도 더욱 안정적으로 유지되 는 것으로 나타났다. 따라서 하악 악교정 수술에서 생흡수성 메 쉬 고정술은 타이타늄 플레이트 고정술보다 골격 안정성이 더 우수할 것으로 추정된다. 이는 재료 자체의 강도가 약함에도 불 구하고, 메쉬의 공간 구조상 고정 스크류의 수와 공간적 배치를 효율적으로 적용할 수 있기 때문이라고 생각된다. 이 점은 유한 요소분석 등의 연구로 추후 규명이 필요하다.

\section{ACKNOWLEDGEMENTS}

We appreciate to Prof. Suk-Keun Lee (Department of Oral Pathology) for helping us in histological interpretation.

\section{CONFLICTS OF INTEREST}

The authors declare that they have no competing interests.

\section{ORCID}

\author{
Min-Keun Kim \\ https://orcid.org/0000-0002-5481-841X \\ Young-Wook Park \\ https://orcid.org/0000-0001-5881-7257
}




\section{REFERENCES}

1. Yamaguchi T, Park SB, Narita A, Maki K, Inoue I. Genomewide linkage analysis of mandibular prognathism in Korean and Japanese patients. J Dent Res 2005;84:255-259. doi: 10.1177/154405910508400309.

2. Lee JY, Kim YK, Yun PY, Lee NK, Kim JW, Choi JH. Evaluation of stability after orthognathic surgery with minimal orthodontic preparation: comparison according to 3 types of fixation. J Craniofac Surg 2014;25:911-915. doi: 10.1097/SCS.0000000000000609.

3. Yamashita Y, Otsuka T, Shigematsu M, Goto M. A longterm comparative study of two rigid internal fixation techniques in terms of masticatory function and neurosensory disturbance after mandibular correction by bilateral sagittal split ramus osteotomy. Int J Oral Maxillofac Surg 2011;40:360-365. doi: 10.1016/j.ijom.2010.11.017.

4. Haug RH. Retention of asymptomatic bone plates used for orthognathic surgery and facial fractures. J Oral Maxillofac Surg 1996;54:611-617. doi: 10.1016/S02782391(96)90644-8.

5. Jorgenson DS, Mayer MF, Ellenbogen RG, Centeno JA, Johnson FB, Mullick FG, Manson PN. Detection of titanium in human tissues after craniofacial surgery. Plast Reconstr Surg 1997;99:976-979.

6. Haers PE, Sailer HF. Biodegradable self-reinforced poly-L/ DL-lactide plates and screws in bimaxillary orthognathic surgery: short term skeletal stability and material related failures. J Craniomaxillofac Surg 1998;26:363-372. doi: 10.1016/S1010-5182(98)80069-3.

7. Shand JM, Heggie AA. Use of a resorbable fixation system in orthognathic surgery. Br J Oral Maxillofac Surg 2000;38: 335-337. doi: 10.1054/bjom.1999.0287.

8. Matthews NS, Khambay BS, Ayoub AF, Koppel D, Wood G. Preliminary assessment of skeletal stability after sagittal split mandibular advancement using a bioresorbable fixation system. Br J Oral Maxillofac Surg 2003;41:179184. doi: 10.1016/S0266-4356(03)00048-2.

9. Cheung LK, Chow LK, Chiu WK. A randomized controlled trial of resorbable versus titanium fixation for orthognathic surgery. Oral Surg Oral Med Oral Pathol Oral Radiol Endod 2004;98:386-397. doi: 10.1016/j.tripleo.2004.02.069.

10. Laine P, Kontio R, Lindqvist C, Suuronen R. Are there any complications with bioabsorbable fixation devices? A 10 year review in orthognathic surgery. Int J Oral Maxillofacial Surg 2004;33:240-244. doi: 10.1006/ijom.2003.0510.

11. Kallela I, Laine P, Suuronen R, Lindqvist C, Iizuka T. Assessment of material-and technique-related complications following sagittal split osteotomies stabilized by biodegradable polylactide screws. Oral Surg Oral Med Oral Pathol Oral Radiol Endod 2005;99:4-10. doi: 10.1016/ j.tripleo.2004.04.017.

12. Landes CA, Ballon A, Tran A, Ghanaati S, Sader R. Segmental stability in orthognathic surgery: hydroxyapatite/PolyL-lactide osteoconductive composite versus titanium miniplate osteosyntheses. J Craniomaxillofac Surg 2014;42: 930-942. doi: 10.1016/j.jcms.2014.01.013.

13. Ueki K, Okabe K, Miyazaki M, Mukozawa A, Moroi A, Marukawa K, Nakagawa K, Yamamoto E. Skeletal stability after mandibular setback surgery: comparisons among unsintered hydroxyapatite/poly-L-lactic acid plate, poly-Llactic acid plate, and titanium plate. J Oral Maxillofac Surg 2011;69:1464-1468. doi: 10.1016/j.joms.2010.06.187.

14. Ono S, Shauver MJ, Chang KW, Chung KC. Outcomes of pyrolytic carbon arthroplasty for the proximal interphalangeal joint at 44 months' mean follow-up. Plast Reconstr Surg 2012;129:1139-1150. doi: 10.1097/ PRS.0b013e31824a2e38.

15. Ueki K, Nakagawa K, Marukawa K, Takazakura D, Shimada M, Takatsuka S, Yamamoto E. Changes in condylar long axis and skeletal stability after bilateral sagittal split ramus osteotomy with poly-L-lactic acid or titanium plate fixation. Int J Oral Maxillofac Surg 2005;34:627-634. doi: 10.1016/j.ijom.2005.02.013.

16. Landes CA, Ballon A. Skeletal stability in bimaxillary orthognathic surgery: P (L/DL) LA-resorbable versus titanium osteofixation. Plast Reconstr Surg 2006;118:703721. doi: 10.1097/01.prs.0000232985.05153.bf.

17. Stockmann P, Böhm H, Driemel O, Mühling J, Pistner $\mathrm{H}$. Resorbable versus titanium osteosynthesis devices in bilateral sagittal split ramus osteotomy of the mandiblethe results of a two centre randomised clinical study with an eight-year follow-up. J Craniomaxillofac Surg 2010;38: 522-528. doi: 10.1016/j.jcms.2010.01.002.

18. Moure C, Qassemyar Q, Dunaud O, Neiva C, Testelin S, Devauchelle B. Skeletal stability and morbidity with self-reinforced $\mathrm{P}$ (L/DL) LA resorbable osteosynthesis in bimaxillary orthognathic surgery. J Craniomaxillofac Surg 2012;40:55-60. doi: 10.1016/j.jcms.2011.01.011.

19. Paeng JY, Hong J, Kim CS, Kim MJ. Comparative study of skeletal stability between bicortical resorbable and titanium screw fixation after sagittal split ramus osteotomy for mandibular prognathism. J Craniomaxillofac Surg 2012; 40:660-664. doi: 10.1016/j.jcms.2011.11.001.

20. Ahn YS, Kim SG, Baik SM, Kim BO, Kim HK, Moon SY, Lim SH, Kim YK, Yun PY, Son JS. Comparative study between resorbable and nonresorbable plates in orthognathic surgery. J Oral Maxillofac Surg 2010;68:287-292. doi: 10.1016/j.joms.2009.07.020.

21. Van Bakelen NB, Buijs GJ, Jansma J, de Visscher JG, Hoppenreijs TJ, Bergsma JE, Stegenga B, Bos RR. Comparison of biodegradable and titanium fixation systems in maxillofacial surgery: a two-year multi-center randomized controlled trial. J Dent Res 2013;92:1100-1105. doi: 10.1177/0022034513508953.

22. Park JM, Park YW. Postoperative stability of fixation 
with absorbables in simultaneous maxillomandibular orthognathic surgery. Maxillofac Plast Reconstr Surg 2010; 32:126-131.

23. Park YW. Bioabsorbable osteofixation for orthognathic surgery. Maxillofac Plast Reconstr Surg 2015;37:6-15. doi: 10.1186/s40902-015-0003-7.

24. Shikinami Y, Matsuse Y, Nakamura T. The complete process of bioresorption and bone replacement using devices made of forged composites of raw hydroxyapatite particles/poly-L-lactide (F-u-HA/PLLA). Biomaterials 2005;26:5542-5551. doi: 10.1016/j.biomaterials.2005. 02.016 .
25. Shikinami Y, Okuno M. Bioresorbable devices made of forged composites of hydroxyapatite (HA) particles and poly-L-lactide (PLLA). Part II: practical properties of miniscrews and miniplates. Biomaterials 2001;22:3179-3211. doi: 10.1016/S0142-9612(01)00072-2.

26. Lee SW, Gyorgy S, Choi JB, Choi JY, Kim SG. Carbon plate shows even distribution of stress, decreases screw loosening, and increases recovery of preoperative daily feed intake amount in a rabbit model of mandibular continuity defects. J Craniomaxillofac Surg 2014;42:e245-251. doi: 10.1016/ j.jcms.2013.09.006. 